\title{
Risk Preference Differentials of Small Groups and Individuals
}

\author{
Robert S. Shupp \\ Ball State University \\ and \\ Arlington W. Williams \\ Indiana University Bloomington
}

August 29, 2006

The Center for Applied Economics and Policy Research resides in the Department of Economics at Indiana University Bloomington. CAEPR can be found on the Internet at:

http://www.indiana.edu/-caepr. CAEPR can be reached via email at caepr@indiana.edu or via phone at 8D-855-4050.

(2006 by Robert S. Shupp and Arlington W. Williams. All rights reserved. Short sections of text, not to exceed two paragraphs, may be quoted without explicit permission provided that full credit, including $\bigcirc$ notice, is given to the source. 


\title{
Risk Preference Differentials of Small Groups and Individuals
}

\author{
by \\ Robert S. Shupp \\ Department of Economics \\ Ball State University \\ Muncie, IN 47306 \\ (e-mail: rshupp@bsu.edu) \\ and \\ Arlington W. Williams \\ Department of Economics \\ Indiana University \\ Bloomington, IN 47405 \\ (e-mail for correspondence and proofs: williama@indiana.edu) \\ Revised, April 2006*
}

\begin{abstract}
This research compares lottery valuation decisions made by individuals with similar decisions made by small groups. There is an extensive social psychology literature addressing group versus individual decision making, but few studies explore this issue in economic contexts with cash rewards. Willingness-topay data elicited from independent samples of individuals and three-person groups in a repeated-measures experimental design reveal that: 1) the variance of risk preferences is generally smaller for groups than individuals, and 2) the average group is more risk averse than the average individual in high-risk situations, but groups tend to be less risk averse in low-risk situations.
\end{abstract}

Pagehead title: Risk Preference Differentials

JEL classification numbers: C91, C92, D80

Keywords: lab experiments, risk preferences, group decisions, certainty equivalents

* The authors gratefully acknowledge constructive comments from Ronald Baker, Timothy Cason, Charles Holt, Steven Kachelmeier, Susan Laury, David Schmidt, Pravin Trivedi, Rusty Tchernis, Konstantin Tyurin, James Walker, Economic Journal editors Leonardo Felli and David de Meza, and anonymous referees. The research has also benefitted from comments by participants at the regional meetings of the Economic Science Association (September 2000), the Purdue University Economic Theory Workshop (April 2001), and Indiana University students enrolled in the E427 and E627 Seminar in Experimental Economics. 


\section{Risk Preference Differentials of Small Groups and Individuals}

Do small groups reveal systematically different risk preferences than individuals and, if so, how do the risk preferences of the individual group members aggregate into a group risk preference? The research reported here explores these topics, motivated by both its importance as a methodological issue in experimental economics and by the long-standing effort in economics and social psychology to describe valuation decisions over risky prospects. Normative models of economic behavior typically utilize a single objective function that implicitly treats all decisions as individual decisions, even those likely to be made through group interaction in the context of families, committees, management teams, etc. This distinction is important, since laboratory experiments almost exclusively elicit decisions from isolated individuals in spite of the fact that group discussion and problem solving is commonplace in many economic environments. Thus, the external validity of results from many experimental studies hinges partially on whether isolated individuals make decisions that are significantly different from groups when faced with identical information about uncertain outcomes.

In the research reported here, this important methodological issue is addressed using data from an experimental design focused on the potential existence of a group versus individual risk preference differential. This experiment assessed the risk preferences of three-person groups and individuals in the context of revealed certainty equivalents for dichotomous lotteries. Nine maximum willingness-to-pay (WTP) decisions for the right to play each of nine different lotteries were elicited in a non-sequential repeatedmeasures experimental design. The lotteries ranged from a 10\% chance of winning \$20 per person (\$60 per group) to a $90 \%$ chance of winning $\$ 20$ per person. Losing lotteries paid \$0. Subjects made cash-motivated decisions as either an individual or group member, not both, yielding statistically independent individual and group samples for each of the nine lotteries. After confirming the existence of significant differences in group versus individual decisions using independent samples, a follow-up experiment explored how individual WTP decisions are aggregated into a group WTP decision. In this two-phase sequenced experimental design, participants made individual decisions and were then randomly assigned to a three-person group. 
The WTP data from both the independent-samples and sequenced experiments reveal that groups were significantly more risk averse than individuals in the higher-risk lotteries. In the lowest-risk lotteries the independent-samples data suggest that groups tend to be less risk averse than individuals, but this finding was not confirmed in the sequenced experiments. Also, group WTP decisions exhibited significantly smaller variance than individual decisions in seven of nine lotteries.

\section{Previous Research Examining Group versus Individual Decisions}

There is a long history of social psychologists investigating differences in group versus individual decisions. Studies dating back to the early 1960s found that groups tend to make riskier decisions than individuals in the context of responses to choice dilemma questionnaires (CDQs). This "risky-shift” finding led to many other CDQ-based studies [see Isenberg (1986) for a more detailed review of this literature] where participants chose actions in hypothetical situations involving risk, but without a salient response-contingent reward structure. Further research confirmed that groups tend to make decisions that differ from those of individuals, however, groups do not always make riskier decisions. Thus, "choice shift” due to "group polarization”, where individual biases are amplified by group discussion, are now the prevailing terms used to summarize the CDQ-based research. Alternatives to the CDQ methodology are also prominent in the more recent social psychology literature.

A comprehensive review by Kerr et al. (1996) concluded "there are several demonstrations that group discussion can attenuate, amplify, or simply reproduce the judgmental biases of individuals” and "research conducted to date indicates that there is unlikely to be any simple, global answer to the question (p. 693).” Group discussion of a task appears to improve performance only when there is a "demonstrably correct" normative solution to the problem under consideration. For the decision task confronted by subjects in the present study, the fact that truthfully revealing WTP for each lottery was the best strategy may have a high degree of demonstrability (especially since this was explicitly stated in the instructions), but the correctness of any particular WTP was likely to be less demonstrable since risk preferences are subjective. It is possible, 
however, that the expected value of each lottery (discussed briefly in the instructions) could emerge as the objective, demonstrably correct, "statistically rational” solution to the WTP problem in the sense that it maximizes expected monetary earnings. This focal-point logic suggests the possibility of a systematic choice shift where groups submit a decision that is more consistent with risk neutrality than is the average of the individual group members. Alternatively, the social psychology literature suggests the possibility of a choice shift rooted in group polarization that leads risk-averse (or risk-preferring) individuals to a group decision that amplifies their risk preferences and moves the group away from the risk-neutral benchmark relative to the average of the individual decisions.

In the absence of a choice shift that alters individual preferences, group discussion can be viewed as unstructured bargaining between heterogeneous agents with fixed preferences that is likely to result in a group WTP decision that simply reflects the average preference of the individuals in the group. Even if a group does not consciously focus on calculating the mean or median of the individual decisions, it is quite possible that an averaging process will emerge naturally from group discussions.

The data analysis presented in Section 3.4 evaluates the validity of specific research conjectures based on this logic. The group-averaging null conjecture states that there will be no systematic difference between the group’s WTP decision and the average of the group members' individual decisions for a specific lottery. The group-shift alternative conjecture states that a systematic difference between the group and average individual decision will be observed. For lotteries where the null conjecture is rejected, the existence of a choice shift toward the risk-neutral focal point is evaluated relative to the alternative of a choice shift away from risk neutrality. Whether the group decision-making process leads to an averaging of individual decisions or to a choice shift via some other preference aggregation process, the variance of group decisions in a given lottery is expected to be smaller than that of individual decisions.

Given the additional complexity and data acquisition costs of implementing experiments with group decisions, it is not surprising that there are so few studies in the experimental economics literature on group versus individual decision making. Also, given economists' natural concern with the use of meaningful 
incentives, it is not surprising that the few studies conducted by economists utilize salient response-contingent cash rewards.

In general, this literature focuses on two possible consequences of having a group rather than an individual make a decision. The first is whether groups make more rational decisions in the sense that their decisions are more in line with the game-theoretic prediction for a given task. The conclusions are mixed on this account. Three studies found evidence that support the conjecture that group decisions are closer to the game-theoretic prediction while two do not. Bornstein and Yaniv’s (1998) ultimatum bargaining study, Cox’s (2002) study involving trust games, and, to a certain extent, Kocher and Sutter's (2005) beauty contest experiments all found that groups do, although not always initially, play closer to the game-theoretic prediction. In contrast, Cason and Mui’s (1997) dictator game study and Cox and Hayne's (forthcoming) firstprice sealed-bid common-value auction experiments found that groups tend to be less rational (or, in some cases, no less irrational) than individuals in the sense that group decisions lie further (or just as far) from the game-theoretic prediction than the decisions made by individuals. The second consequence involves Expected Utility Theory (EUT). Three studies (Bateman and Munro (2005), Bone et al. (1999), and Rockenbach et al.(2001)) investigate whether groups make choices that are more in line with EUT. None of the studies found evidence that EUT describes group decisions under risk any better than it describes individual decisions. Two recent working papers by Harrison et al. (2005) and Baker et al. (2005) explicitly focus on individual versus group risk preference measurement and are thus more closely related to the research reported here. Neither study reports significant risk preference differences between individuals and three-person groups as measured by the count of "safe" choices using the lottery-choice mechanism developed by Holt and Laury (2002). For a more extensive description of many of these studies see the excellent review of literature in Kocher and Sutter (2005). 


\section{Experimental Design and Procedures}

Risk preference differentials are investigated here using certainty equivalents elicited via a lottery valuation task. There are many studies in the economics literature involving similar lottery valuation experiments. While there is considerable variation in the specific decision tasks, experimental procedures, and reward levels utilized, the ratio of the certainty equivalent to the expected value of a dichotomous lottery tends to be higher with low monetary prizes, low probabilities of winning, and the use of minimum selling price (rather than maximum demand price) certainty-equivalent elicitation techniques.

One of these studies in particular influenced the experimental design. Kachelmeier and Shehata (K\&S, 1992) used a lottery valuation experiment in an interesting study of risk preferences using participants from The People’s Republic of China, the United States, and Canada. The primary focus of their research was the effect on Chinese students' risk preferences of using lotteries with very high monetary rewards. K\&S initially relied on selling prices to elicit certainty equivalents. They found "a marked downward curvilinear trend from highly risk-seeking preferences to risk-neutral or slightly risk-averse preferences as the win percentages increase (p. 1124).” In two subsequent trials, K\&S utilized a maximum demand price method to elicit certainty equivalents and found significantly lower numbers. This is consistent with several earlier studies [e.g. Kahneman et al. (1990)], suggesting that the use of the selling price method was a likely reason for the absence of risk aversion in their low win-percentage lotteries. This result is noteworthy, since risk aversion over these lotteries is predicted by prospect theory and supported by data reported by Tversky \& Kahneman (1992). A maximum demand price method was used in the research reported here in order to avoid the so-called "endowment effect” associated with the minimum selling price method.

A total of 100 participants were recruited from undergraduate economics classes at Indiana University, Bloomington. As mentioned, two experimental designs were implemented. Design I was used to investigate the existence of a statistically significant difference between individual and group risk preferences. In this design, each participant made decisions as either an individual or a member of a three-person group, 
thus maintaining strict independence between the individual and group samples for a given lottery. Sixteen participants were used as individual decision makers and forty-eight other participants were randomly assigned to three-person groups. Design II used thirty-six other participants first making decisions as an individual then as a member of a randomly assigned three-person group. This two-phase design probes beyond the existence-of-difference issue addressed in Design I by allowing an initial exploration of how the risk preferences of specific individuals are aggregated into a group risk preference.

\subsection{Design I Procedures}

In this design, decision-making units (individuals or groups) were spatially separated in a large classroom and no communication between units was permitted. The experiment instructions (Appendix A for individuals, Appendix B for groups) were read aloud while the participants followed along on their personal copies. Participants had few questions and did not appear to have difficulty understanding the experimental procedures. After completing the instructions a practice run through the full set of procedures was conducted without monetary rewards. This was followed immediately by a second run for cash rewards. Six separate experimental sessions were completed (two with individual decisions and four with three-person group decisions). Each session lasted less than one hour and the average payout was \$21.98 per participant.

Appendices A and B also contain the text of an overhead shown to subjects outlining the postinstruction sequence of events comprising a run through the experiment. A detailed explanation and discussion of each step follows.

Step 1 - Entry of Lottery Bid Decisions. Each individual or group decision-making unit entered on a record sheet (also in the appendices) nine "bids” corresponding to nine different lotteries with a chance of winning equal to $10 \%$ through $90 \%$ in $10 \%$ increments. In the sessions with bids submitted by individuals, all participants were endowed with \$20 and all lotteries paid either \$20 or \$0. In the sessions with groups, all groups were endowed with $\$ 60$ and all lotteries paid either $\$ 60$ or $\$ 0$. Each group member was paid an equal one-third share of total group earnings. Groups were given a maximum of twenty minutes to discuss the 
problem and agree on the bids to be entered. If there was disagreement when time expired, participants were informed that each group member would independently submit a bid for each lottery and the mean of the three bids would be entered as the group's bid for that lottery. All groups were able to reach unanimous agreement in considerably less than the allotted time.

Step 2 - Random Choice of One Lottery. After all bids were entered on the record sheets, eight of the nine lotteries were randomly eliminated from further consideration. This was accomplished by having each decision-making unit blindly draw a poker chip from a vessel containing nine chips labeled one through nine (corresponding to the 10\% through 90\% chance-of-winning lotteries, as shown on the record sheet). Whatever chip was drawn, the corresponding lottery was the only lottery utilized in the remaining steps of the experiment.

Step 3 - Random Choice of Lottery Purchase Price. After focusing on a single lottery, a random purchase price was determined in the range from $\$ 0$ to $\$ 19.99$ for individuals and $\$ 0$ to $\$ 59.99$ for groups. The four digits comprising the lottery purchase price were established by having participants blindly choose numbered poker chips. To save time, a single purchase price was applied to all lotteries in an experimental session. Decision-making units with bids greater than or equal to the random purchase price bought the right to play the lottery and paid the random purchase price. All others did not play the lottery and thus received a final cash payment equal to their endowment. The instructions carefully explained, and the experimenters verbally emphasized, that submitting a bid equal to maximum willingness to pay was the best strategy in this game.

Step 4 - Lottery Outcome Determination. Finally, for those individuals and groups who purchased a lottery ticket, the lottery outcome was determined by having a participant blindly draw one of ten poker chips numbered zero through nine. For chip draw D, all lotteries with a chance of winning greater than $(10 \times \mathrm{D}) \%$ were declared winners and all others were declared losers. Thus, all lotteries were winners if a zero was drawn and all lotteries were losers if a nine was drawn. Final cash payments for those who played a lottery were equal to the cash endowment - purchase price + lottery earnings. 


\subsection{Design II Procedures}

In this design, each participant first made a set of decisions as an individual, then as a member of a randomly assigned three-person group. It is important to note that the participants were not informed that they would be making a second set of decisions as a member of a group until after collection of their individual decisions, therefore the Design I and Design II procedures are identical through this point. The participants in Design II sessions were spatially separated in a large classroom and the experiment instructions for making an individual decision (Appendix A) were read aloud while the participants followed along on their personal copies. After completing these instructions a practice run through the full set of individual decision procedures was conducted without monetary rewards. The participants were asked to enter their lottery bid decisions (See step 1 above) knowing these decisions were for cash. After collection of these individual decisions, the participants were told that they were now going to make a similar set of decisions as a member of a previously determined and randomly chosen three-person group. They were reassured that the experimenters would return to their individual decisions and play out all lotteries. Before being given a group record sheet, an overhead (Appendix C) was used to explain how the group decision situation differed. After answering any questions, they were instructed to make their group decisions. Upon collection of the group decisions, steps 2 through 4 from above were performed for the individual and then the group decisions. Three separate experimental sessions were completed (each involving twelve participants and thus four groups). As in Design I, all of the Design II groups were able to come to unanimous agreement on their nine bids within the allotted time. Each session lasted less than one and a half hours and the average payout was \$44.72 per participant.

\section{Experimental Results}

The analysis presented below focuses on a decision maker's certainty-equivalent ratio (CER), defined as maximum willingness to pay for a lottery divided by the lottery’s expected value. A CER equal to unity is consistent with risk-neutral preferences, a CER greater than unity is consistent with risk-seeking 
preferences, and a CER less than unity is consistent with risk-averse preferences. ${ }^{1}$ The reporting of results will initially focus on the existence of an individual versus group risk preference difference by aggregating the individual data from both Design I ( $\mathrm{N}=16)$ and Design II $(\mathrm{N}=36)$ and comparing them to the group data from Design I ( $\mathrm{N}=16)$. Since the individual decisions made in Design II sessions occurred first, and without subject knowledge of the subsequent group decision, statistical independence of individual and group decisions is maintained. The presentation of experimental results begins with a simple graphical overview of CERs across lotteries, followed by estimation of a regression model, followed by supporting pairedcomparison tests focusing on individual lotteries. The CER data are then evaluated in the context of riskaversion coefficients calculated assuming a constant relative risk averse utility function over lottery payoffs. Finally, the Design II individual and group CER data are used to investigate how the risk preferences of specific individuals aggregate into a group risk preference.

\subsection{Graphical Overview}

Figures 1, 2, and 3 report the CER mean, median, and standard deviation for individuals and threeperson groups in each of the nine lotteries. Several informal observations emerge from studying these figures. The analysis presented in the next subsection addresses the statistical validity of these informal point-estimate comparisons.

Observation 1. In the $10 \%$ through $40 \%$ lotteries, using either mean or median CERs, groups exhibit more risk aversion than individuals. This differential is substantially smaller using median CERs primarily due to the individual median CER being lower than the individual mean CER. A few highly risk-seeking individuals have a large impact on the individual mean.

\footnotetext{
${ }^{1}$ In the sections that follow, for CERs less than one, smaller (larger) CERs are assumed to correspond to more (less) risk-averse preferences over a specific lottery. Of course, it is possible that either decision errors or motivations other than maximization of expected utility from lottery payoffs can influence willingness-to-pay bid choices. For example, participants might derive nonmonetary utility from the excitement of playing out a lottery or from submitting bids that they feel will either please or displease the experimenter. Furthermore, such anomalous effects might not be symmetric across individuals and groups.
} 
Observation 2. In the $70 \%$ through $90 \%$ lotteries, using either mean or median CERs, individuals exhibit more risk aversion than groups. Both groups and individuals in these high win-percentage lotteries are closer to the risk-neutral benchmark than in the low win-percentage lotteries.

Observation 3. CER dispersion is smaller for groups than individuals in all lotteries, with the dispersion for individuals being substantially greater in the low win-percentage lotteries. Both groups and individuals exhibit smaller CER dispersion in the high win-percentage lotteries.

\subsection{Statistical Analysis}

The analysis begins with a regression model estimated using all 612 observations (9 lotteries x 68 decision-making units) where CER is the dependent variable and the independent variables are: a groupdecision dummy variable (GRP), a set of eight lottery dummy variables (LOTi, i=20, 30, ... ,90, where i corresponds to the lottery win percentage), and eight GRPxLOTi interaction terms. Inclusion of the interaction terms in the model is critical since it is clear from Figure 1 that both the sign and magnitude of mean CER differences due to the group-vs-individual effect vary systematically across the range of lottery win percentages. The constant term gives the predicted CER for individuals in the $10 \%$ lottery. To account for lack of independence across the nine CERs elicited from each individual and group, robust standard errors are utilized where the data are clustered by these within-subject observations. ${ }^{2}$

Table 1 displays the regression coefficient point estimates, robust clustered standard errors, and twotailed significance tests of the coefficients. A Wald test of the null hypothesis that the lottery dummy coefficients are jointly equal to zero is rejected $(\mathrm{p}=0.000)$, as is the null hypothesis that the interaction coefficients are jointly equal to zero $(\mathrm{p}=0.012)$. Of primary interest here is the significance of lottery-specific effects of group vs. individual decision making. This is evaluated using Wald tests of the null hypotheses

${ }^{2}$ For a detailed discussion of the heteroskedasticity-robust Huber/White sandwich estimator of variance in clustered samples see, for example, Cameron and Trivedi (2005, chapter 24, section 24.5). The specific implementation utilized here is documented in Rogers (1993). The results reported below are nearly identical to GLS estimation of a cluster-specific random effects model. 
$(\mathrm{GRP}+\mathrm{GRPxLOTi})=0$ for the $20 \%-90 \%$ lotteries, and GRP $=0$ for the $10 \%$ lottery (where names of independent variables imply the corresponding point estimates of coefficients). The p-values for these tests are included in Figure 4 (discussed further below) - the null hypothesis of no lottery-specific effect is rejected ( $p<0.10$, two-tailed test) in the $10 \%, 20 \%, 30 \%$, and $40 \%$ lotteries, where the mean group CER is below the mean individual CER, and in the $80 \%$ and $90 \%$ lotteries, where the mean group CER is above the mean individual CER. ${ }^{3}$

These formal regression-based results are generally consistent with the informal observations derived from visual inspection of the mean CER data in Figure 1. To further examine the validity of these observations, the analysis now turns to two-sample tests focusing on the significance of CER differences for each lottery. Figure 4 summarizes the results of the regression-based Wald tests referred to above, as well as three additional tests comparing the group and individual CERs for each of the nine lotteries: t-tests and Mann-Whitney U-tests for central tendency equality, and Levene (1960) F-tests for variance equality. The Mann-Whitney and Levene tests do not rely on the underlying populations being normally distributed. Consistent with the Wald tests, the null hypothesis of equal population means is rejected $(\mathrm{p}<0.10)$ using twosample (two-tailed) t-tests for the 10\%, 20\%, 30\%, 40\%, $80 \%$ and $90 \%$ lotteries. The Wald and t-tests are nearly identical in all except the $40 \%$ and $50 \%$ lotteries where the equal variance null hypothesis is not rejected ( $\mathrm{p}>0.10$ ) and thus the degrees of freedom in the t-tests are not adjusted to account for unequal sample variances. Nonparametric Mann-Whitney U-tests also reject $(\mathrm{p}<0.10)$ central tendency equality for the $30 \%$,

${ }^{3}$ Approximately $11 \%$ of the CER observations occur at the fixed lower boundary of the decision space (bid of zero) and 8\% of the CER observations occur at the variable upper boundary of the decision space (maximum bid / expected value of lottery). These boundary observations are asymmetrically distributed across lotteries - $95 \%$ of the CERs at the lower bound occur in the $10 \%-40 \%$ lotteries, and $88 \%$ of the CERs at the upper bound occur in the $60-90 \%$ lotteries. The fact that bids occur at both corners of the decision space suggests the use of a two-limit censored-normal (Tobit) regression model. This is not a conventional example of censoring, however, since the bounds on the random purchase price mean that bids below (above) the lower (upper) bound of the decision space are equivalent to bids equal to the lower (upper) bound. In spite of the fact that the censored-normal model is rooted in very strong distributional assumptions, Wald tests similar to those reported in Figure 4 (with slightly higher p-values) are obtained if a lottery win-percentage variable is used to model heteroscedasticity in the error term. Without this specification of the conditional variance, the lottery-specific effect of group decision making is not significant in the $80 \%$ and $90 \%$ lotteries. 
$40 \%$ and $90 \%$ lotteries. In summary, these two-sample tests support the existence of a significant interaction between the lottery win-percentage and the effect of group decision making. Groups tend to be more risk averse than individuals in the higher-risk (lower win-percentage) lotteries and less risk averse (approaching risk neutral) in the lowest-risk (high win-percentage) lotteries. ${ }^{4}$ Section 3.4 will explore the robustness of these results when a specific mapping of individual to group decisions is observed.

Since risk neutrality is a natural point of reference for risk preference measures, the null hypothesis that the population mean CER $=1$ is evaluated for individuals and groups in each lottery using a one-sample (two-tailed) t-test. For the individual data, the null hypothesis is rejected $(\mathrm{p}<0.10)$ for all lotteries except the high-variance $10 \%$ and $20 \%$ lotteries. ${ }^{5}$ For the group data, the null hypothesis is rejected $(\mathrm{p}<0.10)$ in all lotteries except the $70 \%, 80 \%$, and $90 \%$ lotteries. Similar results are obtained using nonparametric tests except that, for individuals, the null is also rejected in the $20 \%$ lottery.

${ }^{4}$ The existence of a risk preference gender effect was also investigated. Neither two-sample t-tests nor Mann-Whitney tests allow rejection $(\mathrm{p}<0.10)$ of the null hypothesis of equal central tendency for the male and female certainty equivalents in any of the nine lotteries. A regression model employing gender as a between-subjects effect supports this conclusion. Also, the null of homogeneous population variances is rejected in only the $90 \%$ lottery, with the female sub-sample having higher variance than the male subsample. Given the results of these tests and the fact that the volunteer participants (approximately $70 \%$ male and $30 \%$ female) were randomly assigned to three-person groups, it is very unlikely that the gender composition of groups had a significant impact on the group-versus-individual results.

${ }^{5}$ Data collected during demonstration experiments using graduate and advanced undergraduate student subjects enrolled in the Seminar in Experimental Economics at Indiana University suggest that "highly sophisticated" subjects with formal training in statistics, economic theory, and behavioral economics are far more likely to submit individual CERs near the risk-neutral benchmark than the first-year and secondyear undergraduate economics students used in this research. Generalizations from the informal classroom experiments are very difficult, however, since the data were collected under either hypothetical or very low monetary incentives relative to those used in the research reported here. From Holt and Laury (2002), low and hypothetical monetary incentives are predicted to result in less risk-averse decisions. Despite this confounding of effects, it is likely that the subject-sophistication effect is significant. 


\subsection{Calculation of Risk-Aversion Coefficients}

Commenting on the paper by Kachelmeier and Shehata (K\&S, 1992), Ortona (1994) makes the point that CERs will approach unity monotonically as the lottery win percentage increases if one assumes a stable exponential utility function over lottery payoffs with a constant risk-preference coefficient. Thus, the K\&S observation that mean CERs fall toward unity as the lottery win percentage increases (interpreted by K\&S as revealing less risk-seeking behavior) could be consistent with a fixed risk coefficient utility function. While this observation appears to be roughly consistent with their CER data, Kachelmeier and Shehata's (1994) reply shows that the risk preferences implied by their CER data are unstable. For their high-prize condition, the mean risk coefficients presented by K\&S tend toward less risk-seeking, and eventually risk-averse, choices as the lottery win percentage increases.

Figure 5 displays median risk-aversion coefficients calculated for both groups and individuals in each of the nine lotteries, using a constant relative risk-averse utility function. ${ }^{6}$ The figure illustrates fairly stable median risk-aversion coefficients for both groups and individuals over the $10 \%$ through $60 \%$ lotteries. As the win percentage increases beyond this range, groups reveal less risk aversion in the 70\% through $90 \%$ lotteries and individuals follow this pattern in the $80 \%$ and $90 \%$ lotteries. Thus, the risk-aversion coefficients obtained from the CER data reported here are much more stable than those reported by K\&S (1994). There is, however, movement toward the risk-neutral benchmark in the highest win-percentage lotteries, which is similar to the pattern seen in the K\&S minimum selling price CER data.

${ }^{6}$ Letting X represent the elicited certainty equivalent, $\mathrm{P}$ the probability of winning Y dollars, and (1P) the probability of winning zero dollars, a constant relative risk-averse utility function over lottery payoffs implies $\mathrm{X}^{1-\mathrm{r}}=\mathrm{P}\left(\mathrm{Y}^{1-\mathrm{r}}\right), \mathrm{r} \neq 1$. Thus, $\mathrm{X}=\mathrm{P}^{1 /(1-\mathrm{r})} \mathrm{Y}$ and the $\mathrm{CER}=\mathrm{X} /(\mathrm{PY})=\mathrm{P}^{\mathrm{r} /(1-\mathrm{r})}$, where $\mathrm{r}=0$ implies risk neutrality, $\mathrm{r}>0$ implies risk aversion, and $\mathrm{r}<0$ implies risk-seeking preferences. Solving for $\mathrm{r}$, the coefficient of risk aversion, yields $r=\ln$ CER / ( $\ln P+\ln$ CER). Of the 612 CER observations (468 from individuals and 144 from groups), 66 are equal to zero (46 from individuals and 20 from groups) reflecting a willingness-topay of $\$ 0$ in low win-percentage lotteries. For these instances where $r$ is undefined, $r$ is set equal to one when calculating the medians shown in Figure 5. Also, the figure focuses on the median r, rather than the mean, due to a few extreme negative $r$ estimates in high win-percentage lotteries that have a large effect on the mean. 


\subsection{Aggregation of Individual Decisions into a Group Decision}

The objective of this section is to use the Design II individual $(\mathrm{N}=36)$ and group $(\mathrm{N}=12)$ data to explore how individual group members' CERs are aggregated into a group CER, and, in doing so, to evaluate the robustness of the basic results from the independent-samples data presented in the previous sections. The null hypothesis that the Design I and Design II group-decision samples are drawn from populations with identical central tendency can not be rejected ( $p>0.20$ in Mann-Whitney tests for each of the nine lotteries). Thus, it appears that group decisions are not, on average, significantly affected by the fact that Design II participants had previously submitted bids as individuals (but had not seen the outcome from those decisions) ${ }^{7}$

The empirical validity of a priori conjectures about how individual decisions aggregate into a group decision is evaluated using descriptive statistics and Wilcoxon matched-pairs tests. For each lottery the groupaveraging null conjecture, that the group CER does not systematically differ from the average of the individual group members' CER decisions (hereafter, average individual CER), is evaluated relative to the group-shift alternative conjecture. The group focal-point conjecture, that group discussion tends to move the group CER toward the risk-neutral benchmark relative to the average individual CER, is also considered as a specific type of choice shift. The results presented in the previous sections suggest that the group-averaging null conjecture will be rejected in the low $(10 \%$ - 40\%) win-percentage lotteries, where groups appear to be more risk averse than individuals, and the highest (80\% - 90\%) win-percentage lotteries, where groups appear

${ }^{7}$ While this small-sample finding is suggestive, it does not eliminate the possibility that the Design II group decisions reflect a confounding of a group-discussion effect and a pure decision-sequence effect. The problem is that individual CERs are not observed in the second phase of the experiment immediately before group discussion occurs. It is assumed that there is no systematic change in individual CERs from the first to the second phase, which are separated by only a few minutes. Sessions with sequential individual decisions could be used to test for the existence of learning or order effects that are independent of the effects of group discussion. Focusing the Design II subject payment funds on the individual-then-group sequence allowed a larger sample to be collected in this important treatment, which most directly addresses a referee's suggestion to check the robustness of the (Design I) independent-samples results in a sequenced environment where group decisions can be compared to the specific individual decisions of group members. A careful investigation of decision-sequence effects in this setting remains a topic for future research. 
to be less risk-averse than individuals. The independent-samples analysis suggests that the group focal-point conjecture will be rejected in all but perhaps the two highest (80\% - 90\%) win-percentage lotteries.

Table 2 displays descriptive statistics and Wilcoxon matched-pairs tests comparing, for each lottery, each group’s CER with the mean CER of the three group members. The table reveals that, in the high-risk (low win-percentage) lotteries, the group CER tends to be substantially less than the mean of the group members' individual CERs. This difference is significant $(\mathrm{p}<0.10)$ in the $10 \%$ through $40 \%$ lotteries. These rejections of the group averaging null in the low win-percentage lotteries are consistent with the prior independent-samples analysis. However, unlike the independent-samples analysis, the group-averaging null cannot be rejected for either the $80 \%$ or $90 \%$ lotteries. The data reveal that this is in part due to the fact that the individuals in the Design II sample are, on average, less risk averse in the high win-percentage lotteries than the individuals in the Design I sample. ${ }^{8}$

Further study of the Design II individual and group data in the high-risk lotteries supports the conclusion that group discussion leads to more risk-averse decisions. In each of the four highest-risk lotteries 10 of the 12 group CER observations, 83.3\%, are more risk-averse than the mean individual CER. In contrast, over the five lowest-risk lotteries $48.3 \%$ of the group CERs are more risk-averse than the mean individual CER. Part of the significant choice shift in the four highest-risk lotteries is consistent with an averaging process that underweights the upper extremum of the individual CERs. But 25\% of the group CERs that are less than the mean individual CER are also less than the most risk-averse group member's individual CER, and are thus inconsistent with an averaging process. The lower extremum of the individual CERs in the four highest-risk lotteries is adopted as the group CER in 39.6\% of cases, and is thus a weak focal point outcome for the choice shift toward increased risk aversion. In the five lowest-risk lotteries this outcome occurs in 8.3\% of cases. The Design II data are thus consistent with the prior independent-samples analysis with regard

${ }^{8}$ The individual median CER was also considered in the evaluation of the group averaging null conjecture. Results using the median are qualitatively similar, but the null is rejected $(\mathrm{p}<0.10)$ in only the $10 \%$ though $30 \%$ lotteries. 
to decisions in the highest risk lotteries and confirm, albeit with a small sample, that group discussion tends to induce a choice shift toward increased risk aversion in high-risk situations.

As a refinement of the group-shift alternative conjecture, the group focal-point conjecture implies that group CERs will be closer to the risk-neutral benchmark than the corresponding individual mean CER. This is true for only 33.3\% (12 of 36), 30.6\% (11 of 36), and 41.7\% (15 of 36) of the paired observations over the three highest, medium, and lowest risk lotteries, respectively. This evidence, in combination with the finding that the group averaging null conjecture can not be rejected in the $50 \%$ through $90 \%$ lotteries, implies that there is not general support for the group focal-point conjecture in the Design II data.

\section{Summary and Discussion}

The research presented here documents an economic decision-making environment using salient monetary rewards where statistically significant risk-preference differentials are observed for group versus individual decision makers. Use of a maximum willingness-to-pay procedure eliminates the preponderance of seemingly risk-seeking choices observed by Kachelmeier and Shehata (1992) using a minimum compensation-demanded procedure and is generally consistent with the levels of risk aversion found in recent research by Holt and Laury (2002). A regression model and two-sample tests using independent group (N=16) versus individual ( $\mathrm{N}=52)$ willingness-to-pay certainty equivalents support the following general conclusions. Conclusion 1. Certainty equivalent ratios vary significantly across lotteries as the win percentage varies from $10 \%$ to $90 \%$. For both groups and individuals, the median CER tends to increase toward the risk-neutral benchmark as the lottery win percentage increases. The corresponding median coefficients of constant relative risk aversion are fairly stable across the $10 \%$ through $60 \%$ lotteries, but eventually move toward the riskneutral benchmark over the $70 \%$ through $90 \%$ lotteries.

Conclusion 2. For higher-risk lotteries with a win percentage of $40 \%$ or lower, the average group is significantly more risk averse than the average individual. 
Conclusion 3. For the lowest-risk lotteries with a win percentage of $80 \%$ and $90 \%$, the average group is approximately risk neutral and significantly less risk averse than the average individual.

Conclusion 4. For lotteries with a win percentage of 50\%, 60\%, and 70\%, the average group and the average individual are both risk averse and are not significantly different.

Conclusion 5. The variance of CERs is lower for groups than for individuals in all lotteries. This difference is significant for all except the $40 \%$ and $50 \%$ lotteries. In general, CER variance tends to decrease as the lottery win-percentage increases.

The effect on risk preference measurement of using three-person groups instead of individuals as decision makers is more complex than was anticipated prior to conducting this research. Rather than a simple uniform shift of certainty equivalent ratios across different win-percentage lotteries, the magnitude and possibly the direction of the group effect appears to depend on the inherent riskiness of the property right being considered for acquisition. Analysis of the smaller sample of Design II data (thirty-six individual decisions followed by twelve three-person group decisions) supports the conclusion that group discussion leads to a significant shift toward more risk aversion in the four highest risk lotteries, but does not reveal significant separation of the group CER and the mean individual CER in any of the five lowest risk lotteries.

For both groups and individuals, as the win percentage increases: 1) the median CER trends upward toward unity (see Figure 2), 2) CER dispersion is reduced (see Figure 3), and 3) the coefficient of relative risk aversion eventually decreases toward the risk-neutral benchmark (Figure 5). Why do both groups and individuals reveal lower variance and more risk-neutral bids as the risk associated with the lottery decreases? One possible explanation focuses on differentials across lotteries in the monetary incentive to submit statistically rational risk-neutral bids that maximize expected earnings in this experimental setting. For each 
of the nine \$20 lotteries, Figure 6 shows expected earnings as a function of the bid. ${ }^{9}$ Each function’s peak occurs at the risk-neutral bid for that lottery, so bids consistent with either risk aversion or risk seeking lead to a loss in expected earnings relative to the risk-neutral bid. Figure 7 translates the expected earnings curves shown in Figure 6 into expected monetary loss (relative to the risk-neutral benchmark) as a function of the CER. ${ }^{10}$ The expected loss functions reveal that, using CER as the bid metric, the monetary cost of deviating from the risk-neutral bid increases as the lottery win percentage increases. For example, in the $20 \%$ lottery, submitting a bid that generates a CER of .5 results in an expected loss of $\$ 0.10$ relative to risk-neutral expected earnings of $\$ 20.40$. In the $80 \%$ lottery, a bid generating a CER of .5 results in an expected loss of $\$ 1.60$ relative to risk-neutral expected earnings of $\$ 26.40$. The figures also reveal that the earnings differential over the interval from $C E R=1$ to $C E R=0$ ranges from $\$ 8.10$ (\$28.10 - \$20.00) in the $90 \%$ lottery to $\$ 0.10$ (\$20.10 - \$20.00) in the $10 \%$ lottery.

Given the relatively small incentive to bid precisely in the higher-risk lotteries, the accuracy of bids as a measure of true certainty equivalents is perhaps reduced relative to the lower-risk lotteries. While previous research suggests that this reduced incentive is not expected to affect the central tendency of the sample bid distributions, it is likely to increase their variance (see Smith and Walker, 1993). Both individuals and groups are seemingly responsive to the magnitude of the expected monetary losses associated with deviations from expected-value bidding, as evidenced by the reduced variance of bids and the trend toward

${ }^{9}$ If a winning lottery pays $\$ 20$, a losing lottery pays $\$ 0$, decision makers receive a $\$ 20$ endowment, and the random purchase price is uniformly distributed with supports at $\$ 0$ and $\$ 19.99$, then expected earnings in a specific lottery $=\left(\mathrm{P}_{\mathrm{BUY}} \cdot\left\{\$ 20-\mathrm{E}[\right.\right.$ Price $\mid$ Bid $\geq$ Price $\left.\left.]+\left[\mathrm{P}_{\mathrm{WIN}} \cdot \$ 20\right]\right\}\right)+\left(\left\{1-\mathrm{P}_{\mathrm{BUY}}\right\} \cdot \$ 20\right)$, where: $\mathrm{P}_{\mathrm{BUY}}=\mathrm{Bid} / 19.99$ is the probability of buying a lottery conditional on the submitted bid, $\mathrm{E}$ (Price $\mid$ Bid $\geq$ Price $)=\operatorname{Bid} / 2$ is the expected purchase price conditional on having bought the lottery, and $\mathrm{P}_{\mathrm{wIN}}$ is the probability of winning the lottery. For example, a risk-neutral bid of $\$ 10$ in the $50 \%$ lottery yields expected earnings of $(.50025 \cdot\{\$ 20-\$ 5+\$ 10\})+(.49975 \cdot \$ 20)=\$ 22.50$, rounding to the penny. Prior to the procedural step where only one lottery is selected for further play (see section 2.1), each lottery has a 1/9 probability of being chosen. At this stage a risk-neutral bidder has expected earnings of $\$ 23.17$ over all nine lotteries.

${ }^{10}$ Only the risk-averse CER range is shown in Figure 7 since the functions are symmetric around $\mathrm{CER}=1$ and the majority of the observations are consistent with risk aversion. 
expected-value bidding as the lottery win percentage increases. The independent-samples analysis indicates that group CERs are on average significantly closer to the risk-neutral benchmark than individual CERs only in the highest win-percentage lotteries. While this finding is not present in the Design II matched-pairs comparison of group versus mean individual CERs, it suggests that group discussion is more likely to facilitate outcomes that are consistent with risk neutrality when the decision costs required to reach this solution are offset by a sufficiently large expected monetary gain. 


\section{References}

Baker, R. J., Laury, S. K., and Williams, A.W. (2005). 'Comparing group and individual behavior in lotterychoice experiments’, unpublished manuscript, Indiana University.

Bateman, I. and Munro, A. (2005). 'An experiment on risky choice amongst households', ECONOMIC JOURNAL, vol. 115 (March), pp. C176-C189.

Becker, G. M., DeGroot, M. H. and Marschak, J. (1964). 'Measuring utility by single-response sequential method’, Behavioral Science, vol. 9 (July), pp. 226-32.

Bone, J., Hey, J., and Suckling, J. (1999). 'Are groups more (or less) consistent than individuals?', Journal of Risk and Uncertainty, vol. 8, pp. 63-81.

Bornstein, G. and Yaniv, I. (1998). 'Individual and group behavior in the ultimatum game: are groups more rational players’, Experimental Economics, vol. 1, pp. 101-08.

Cameron, A.C. and Trivedi, P. K. (2005). Microeconometrics, New York: Cambridge University Press.

Cason, T. N. and Mui, V. (1997). 'A laboratory study of group polarisation in the dictator game', ECONOMIC JOURNAL, vol. 107 (September), pp. 1465-83.

Cox, J. C. and Hayne, S. C. (forthcoming), 'Barking Up the Right Tree: Are Small Groups Rational Agents?', Experimental Economics.

Cox, J. C. (2002), 'Trust, reciprocity, and other regarding preferences: group vs. individual and male vs. female', in (R. Zwick, and A. Rapoport, eds.), Advances in Experimental Business Research , pp. 33150, Dordrecht: Kluwer Academic Publishers.

Harrison, G. W., Lau, M. I., Rutström, E. E., and Tarazona-Gómez, M. (2005). 'Preferences over social risk', unpublished manuscript, University of Central Florida.

Holt, C. A. and Laury, S. K (2002). 'Risk aversion and incentive effects', American Economic Review, vol. 92 (December), pp. 1644-55.

Isenberg, D. J. (1986). 'Group polarization: a critical review and meta analysis', Journal of Personality and Psychology, vol. 50, pp. 1141-51.

Kachelmeier, S. J. and Shehata, M. (1992). 'Examining risk preferences under high monetary incentives: experimental evidence from the Peoples's Republic of China', American Economic Review, vol. 82 (December), pp. 1120-41.

Kachelmeier, S. J. and Shehata, M. (1994). 'Examining risk preferences under high monetary incentives: reply’, American Economic Review, vol. 84 (September), pp. 1105.

Kahneman, D., Knetsch, J. L. and Thaler, R. H. (1990). 'Experimental tests of the endowment effect and the coase theorem', Journal of Political Economy, vol. 98 (December), pp. 1325-48. 
Kerr, N. L., MacCoun, R. J. and Kramer, G. P. (1996). 'Bias in judgement: comparing individuals and groups’, Psychological Review, vol. 103, pp. 687-719.

Kocher, M. G. and Sutter, M. (2005). 'The decision maker matters: individual versus group behaviour in experimental beauty-contest games’, ECONOMIC JOURNAL, vol. 115 (January), pp. 200-23.

Levene, H.(1960). 'Robust tests for the equality of variance', in (I. Olkin, ed.), Contributions to Probability and Statistics, pp. 278-92, Palo Alto, CA: Stanford University Press.

Ortona, G. (1994). 'Examining risk preferences under high monetary incentives: comment', American Economic Review, vol. 84 (September), pp. 1104.

Rogers, W. H. (1993). 'Regression standard errors in clustered samples’, Stata Technical Bulletin Reprints, vol. 3, pp. 88-94.

Rockenbach, B., Sadrieh, A., and Matauschek, B. (2001). 'Teams take the better risks', unpublished manuscript, University of Erfurt.

Smith, V. L. and Walker J. M. (1993). 'Monetary rewards and decision costs in experimental economics', Economic Inquiry, vol. 31 (April), pp. 245-61.

Tversky, A. and Kahneman, D. (1992). 'Advances in prospect theory: cumulative representation of uncertainty’, Journal of Risk and Uncertainty, vol. 5, pp. 297-323. 
Table 1. Regression Model

Dependent Variable: CER = Bid / Expected Value of Lottery

\begin{tabular}{ccccc}
$\begin{array}{c}\text { Independent } \\
\text { Variable }\end{array}$ & $\begin{array}{c}\text { Coefficient } \\
\text { Estimate }\end{array}$ & $\begin{array}{c}\text { Robust Clustered } \\
\text { Standard Error }\end{array}$ & \multicolumn{2}{c}{ Ho: Coefficient $=0$} \\
2-tailed p-value
\end{tabular}

Total number of observations $=612=68$ clusters of 9 observations

Model: $\mathrm{F}(17,67)=7.31, \mathrm{p}=0.000$; R-squared $=0.066$

Table 2. Comparison of Group CER and Average of Three Group Members' Individual CERs

\begin{tabular}{ccccc}
$\begin{array}{c}\text { Lottery } \\
\text { Win }\end{array}$ & \multicolumn{2}{c}{$\begin{array}{c}\text { Mean CER } \\
\text { Percentage }\end{array}$} & $\begin{array}{c}\text { Mean Difference } \\
\text { Group CER minus the Group } \\
\text { Members' Mean Individual CER }\end{array}$ & $\begin{array}{c}\text { Wilcoxon Matched-Pairs Test } \\
\text { Houp CER = Members' Mean CER } \\
\text { 2-tailed p-value (N=12) }\end{array}$ \\
\hline $10 \%$ & 1.288 & 0.354 & -0.934 & 0.013 \\
$20 \%$ & 0.835 & 0.365 & -0.471 & 0.021 \\
$30 \%$ & 0.829 & 0.456 & -0.374 & 0.028 \\
$40 \%$ & 0.851 & 0.510 & -0.340 & 0.041 \\
$50 \%$ & 0.912 & 0.826 & -0.086 & 0.326 \\
$60 \%$ & 0.995 & 0.924 & -0.071 & 0.209 \\
$70 \%$ & 0.987 & 0.954 & -0.033 & 0.814 \\
$80 \%$ & 0.989 & 0.996 & 0.007 & 0.638 \\
$90 \%$ & 0.961 & 0.978 & 0.018 & 0.456
\end{tabular}


Fig. 1. Mean Certainty-Equivalent Ratio (CER) Comparison

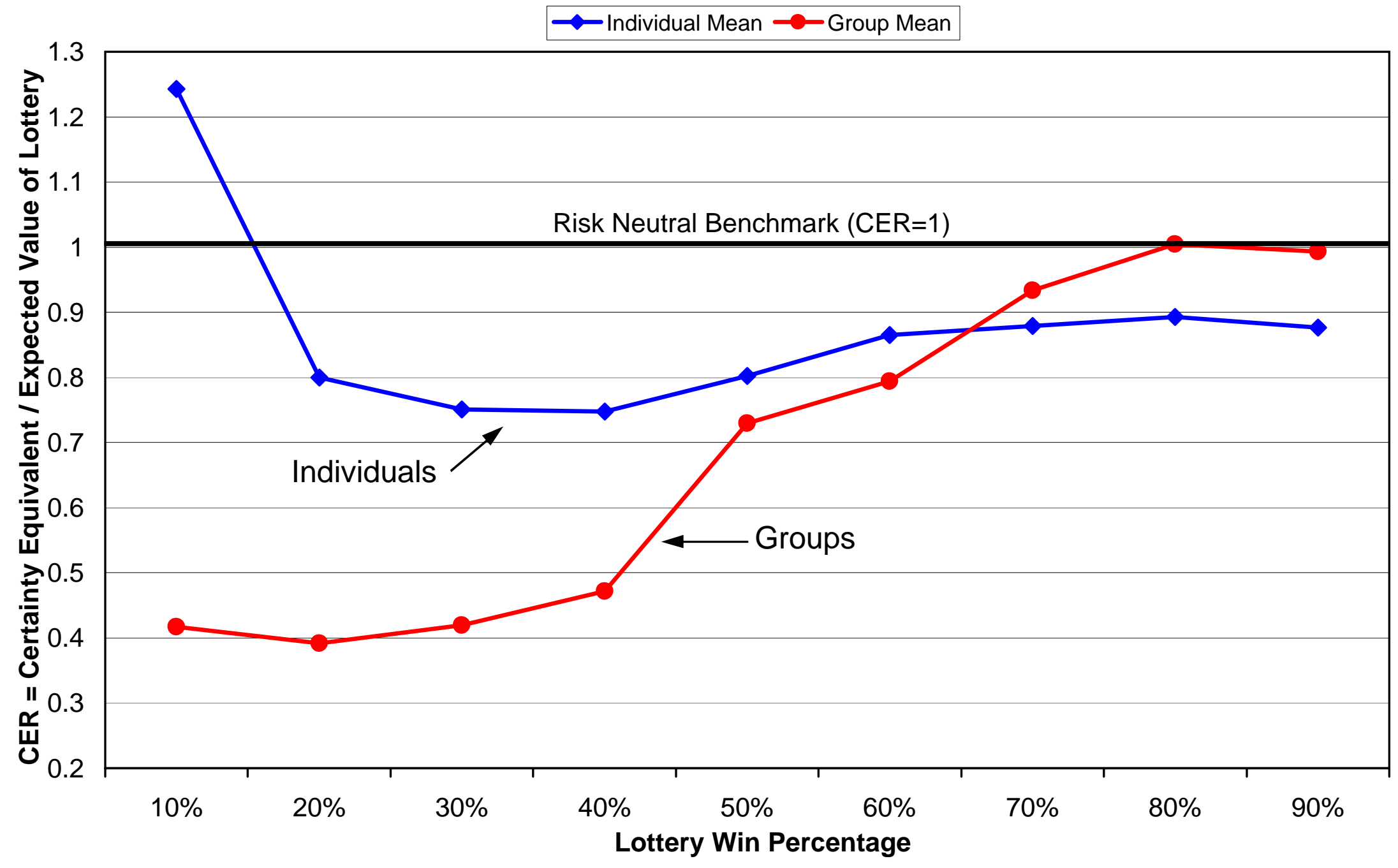


Fig. 2. Median Certainty-Equivalent Ratio (CER) Comparison

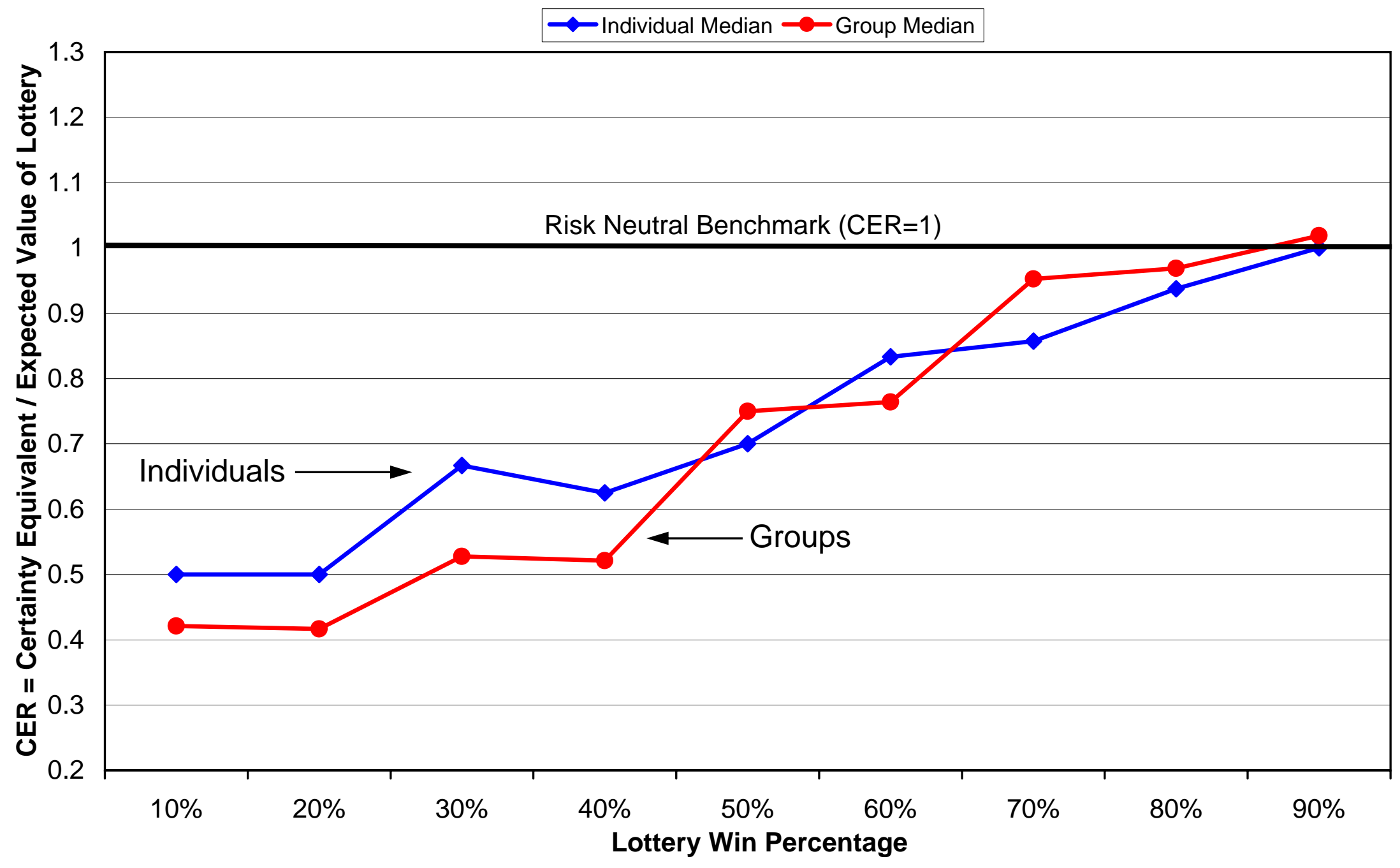


Fig. 3. Certainty-Equivalent Ratio (CER) Standard Deviation Comparison

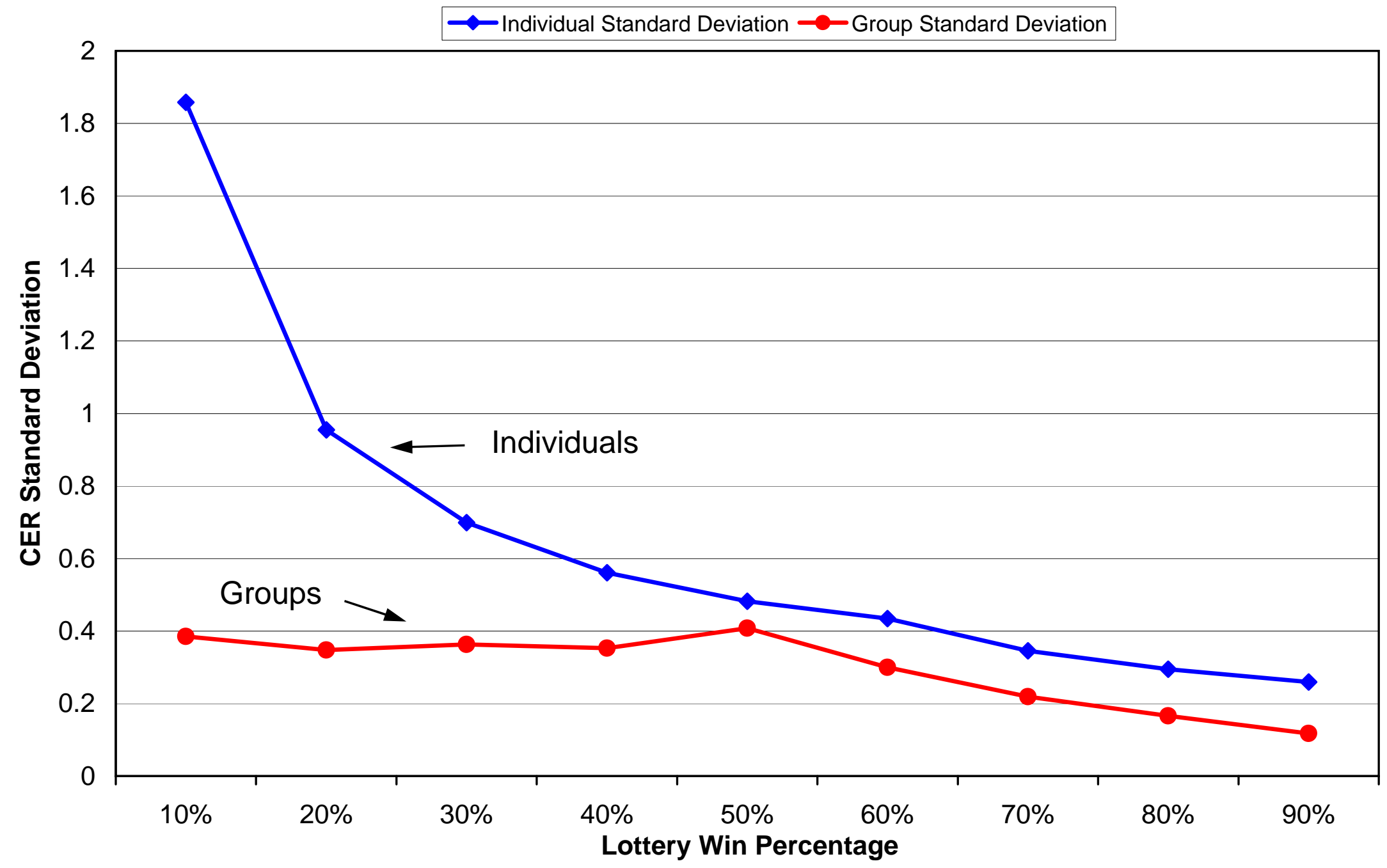


Fig. 4. Probability of Type-I Error: Groups vs. Individuals

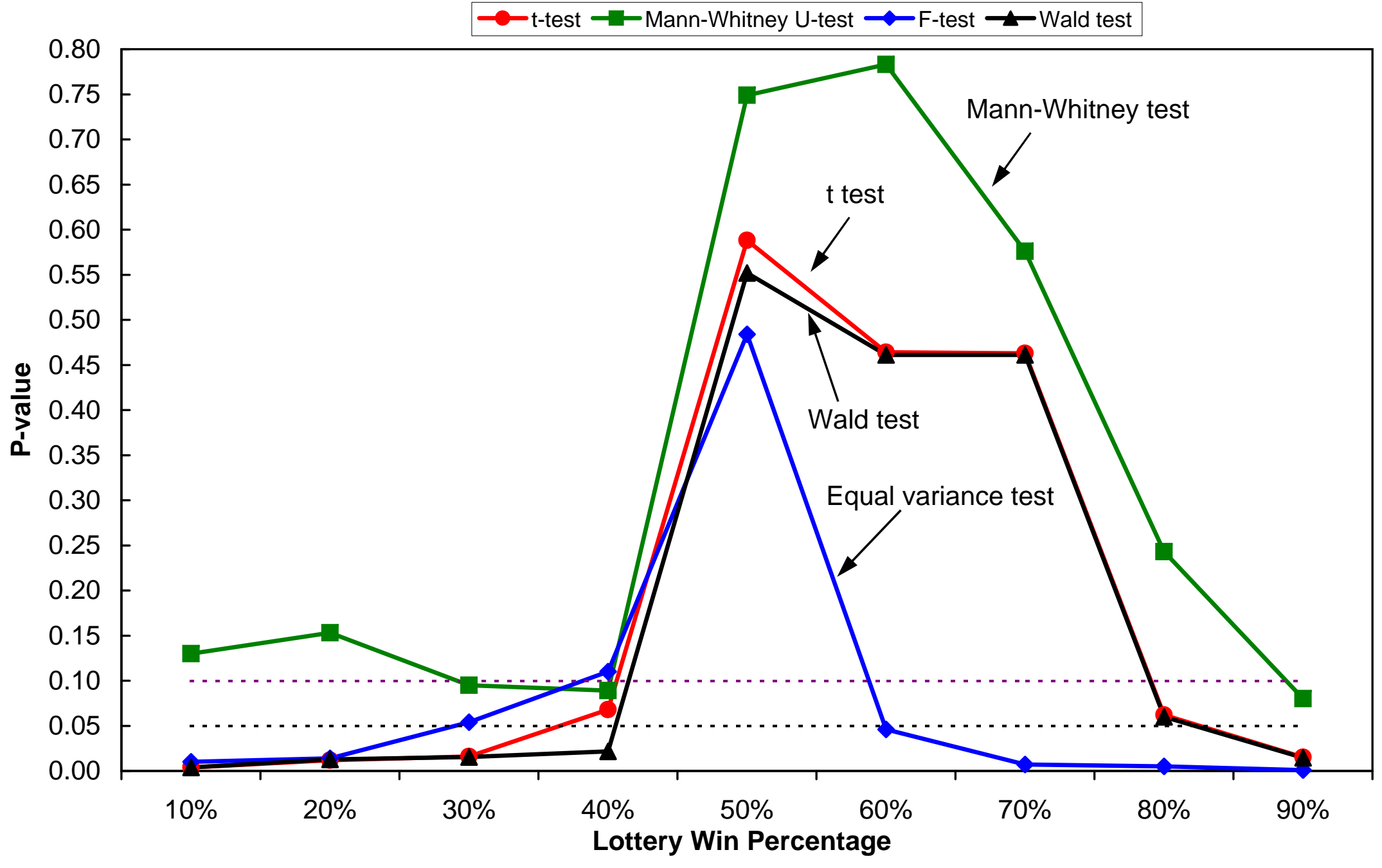


Fig. 5. Median Coefficient of Risk Aversion Comparison

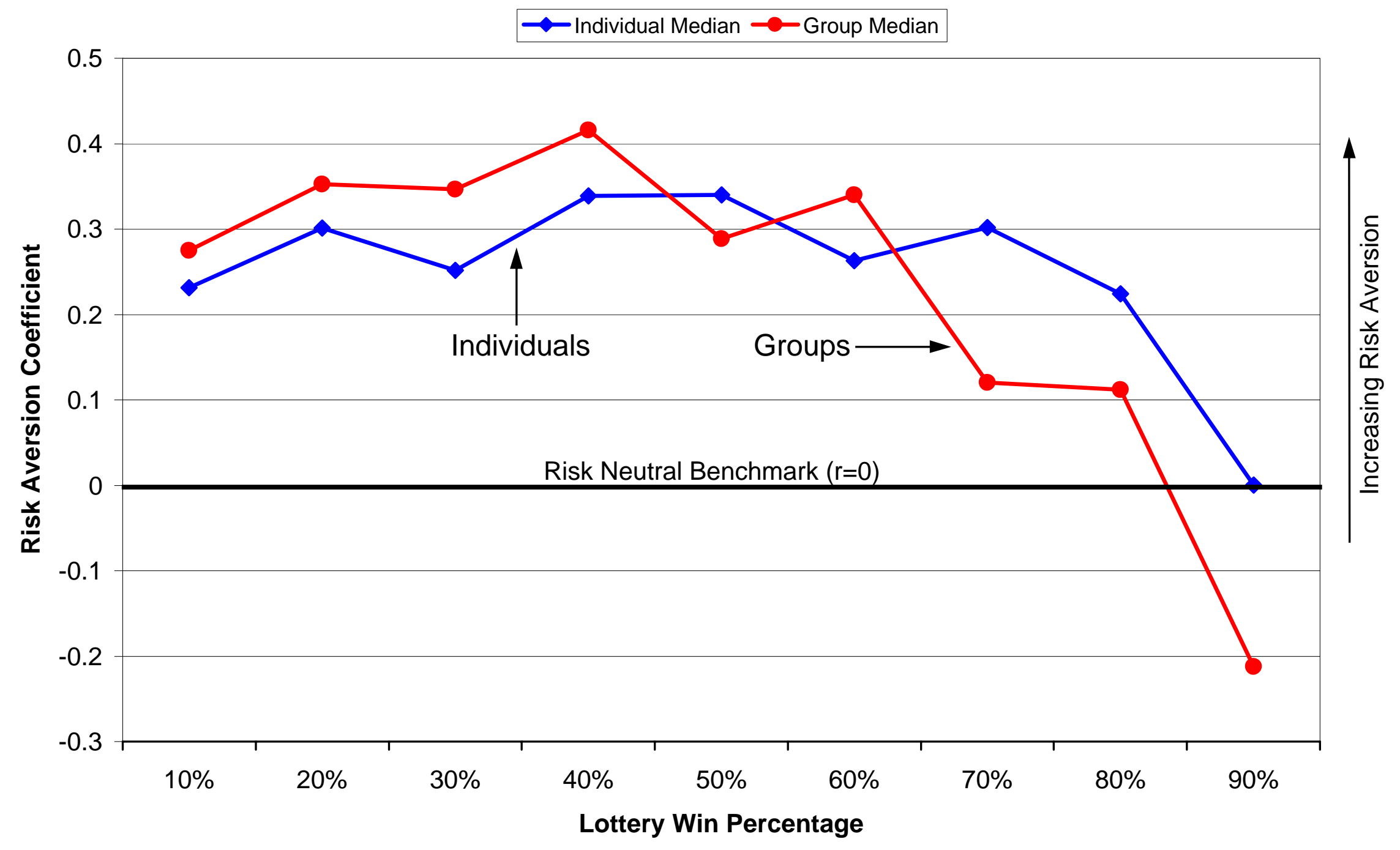


Fig. 6. Expected Earnings Functions

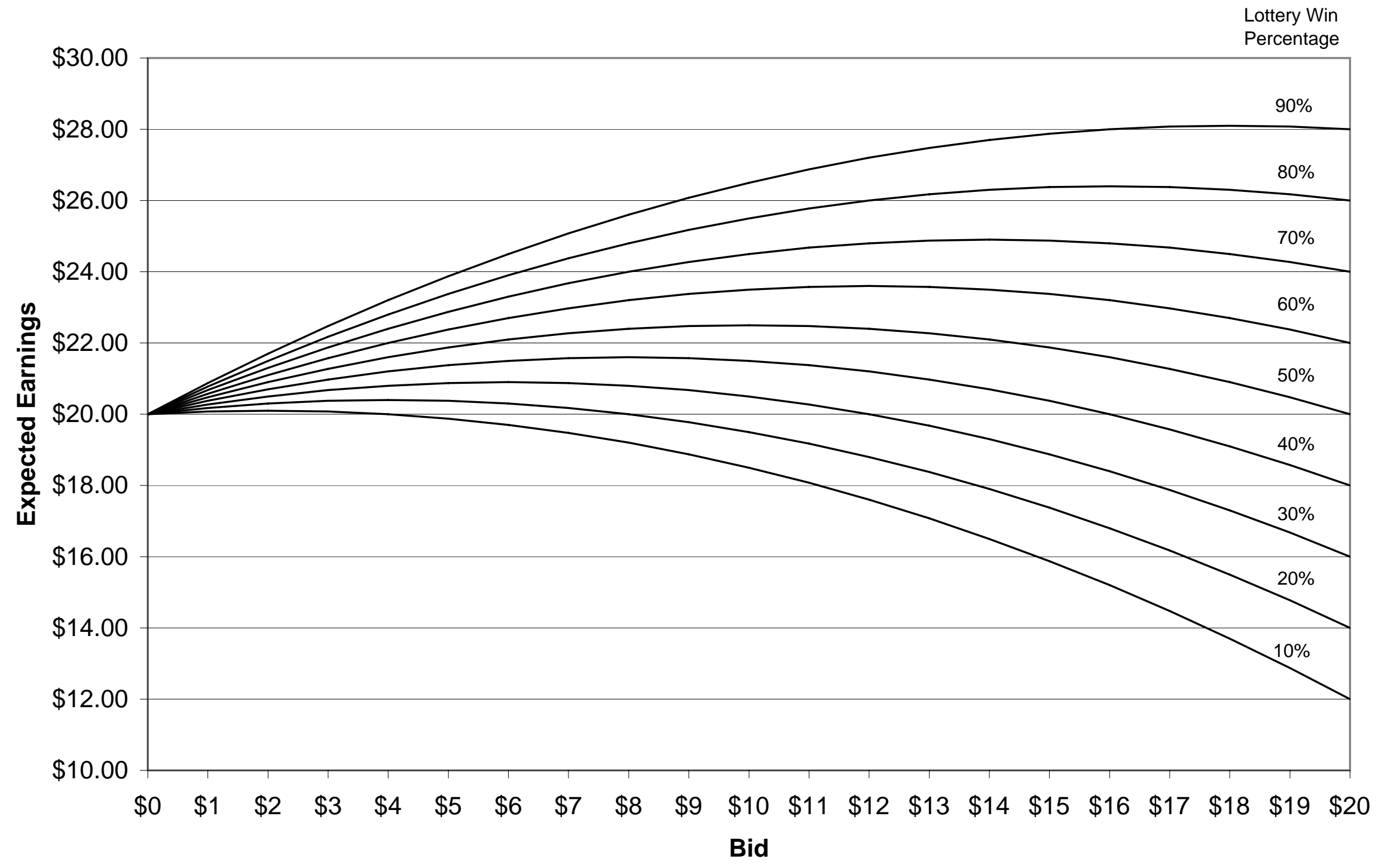


Fig. 7. Expected Monetary Loss Functions

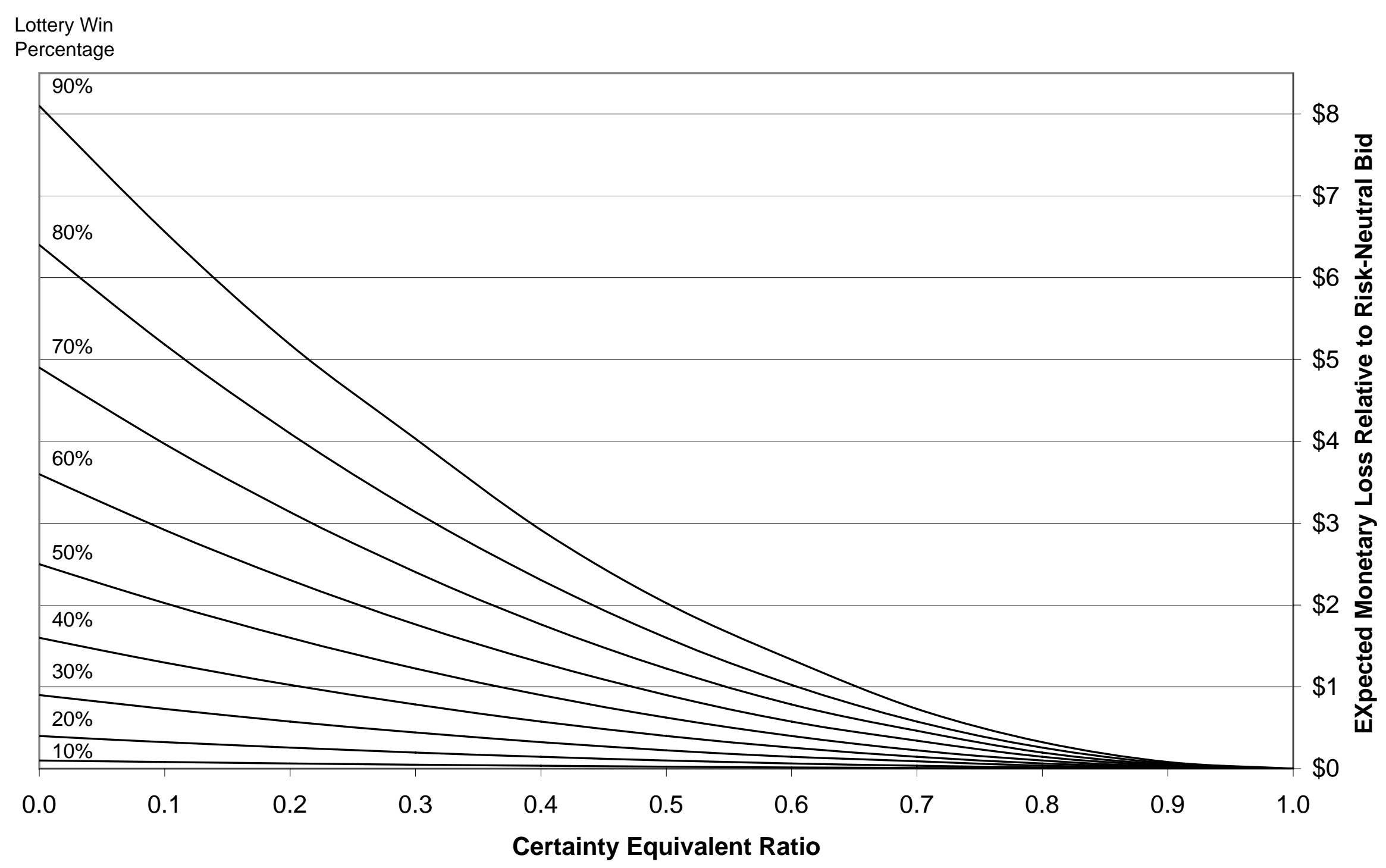




\section{"Risk Preference Differentials of Small Groups and Individuals" Appendices}

Appendix A - Instructions, Record Sheet, and Overhead for Sessions with Individuals

Appendix B - Instructions, Record Sheet, and Overhead for Sessions with Three-Person Groups

Appendix C - Overhead for Design II Transition from Individual to Group Decisions 


\section{Appendix A - Instructions, Record Sheet, and Overhead for Sessions with Individuals}

This is an experiment in behavioral economics focusing on individual valuation of events (called lotteries) that have uncertain outcomes. You are starting with a money endowment of $\$ 20$. This $\$ 20$ can be used to purchase the right to play a lottery (i.e. buy a lottery ticket). Since the outcome of a lottery is uncertain, you might win more money or lose some of your $\$ 20$ endowment through participation in the experiment. At the conclusion of the experiment you will be paid your final earnings privately in cash.

Before getting into the details of the experimental procedures and the decisions you will make, it is important that you understand exactly what is meant by the term "lottery".

\section{What is a lottery?}

In this experiment, a lottery is a chance to win a monetary prize of $\$ 20$. There are nine possible lotteries in today's experiment. The nine lotteries are associated with the following chances of winning: $90 \%, 80 \%, 70 \%, 60 \%, 50 \%$, $40 \%, 30 \%, 20 \%, 10 \%$. For example, consider the lottery with a $70 \%$ chance of winning. If this lottery was run many times, the player would win (receive \$20) $70 \%$ of the time and lose (receive $\$ 0$ ) $30 \%$ of the time. Using formal statistical terminology, the "expected value" or average payout from this lottery is .7x $\$ 20=\$ 14$. This is the average payout after many repetitions, in any one lottery the payout is either $\$ 20$ or $\$ 0$. [Are there any questions?]

\section{How is the outcome of a lottery determined?}

To determine whether a lottery pays out $\$ 20$ or $\$ 0$, a number between 0 and 9 will be randomly drawn. The random number will be determined using 10 poker chips numbered 0 through 9 drawn from a bucket. If the number times 10 is less than the stated chance of winning $\$ 20$, the lottery pays $\$ 20$. If the number times 10 is greater than or equal to the stated chance of winning, the lottery pays $\$ 0$. For example, the $70 \%$ lottery pays $\$ 20$ if the random number drawn is $0,1,2,3,4,5$ or 6 . This lottery pays $\$ 0$ if the random number drawn is 7,8 , or 9 . [Are there any questions?]

\section{How do I purchase the right to play a lottery?}

Now that you understand how the lotteries work, it's time to explain how you can purchase the right to play one of the nine lotteries. There are three phases to this process: a bid decision phase, a choice of lottery phase, and a purchase price determination phase.

\section{Bid Decision Phase}

In the bid decision phase you will enter (on the attached Experiment Record Sheet) the maximum amount that you are willing to pay for the right to play each of the nine lotteries. These nine maximum willingness-to-pay decisions are your "bids" for the nine lotteries. The minimum bid is $\$ 0$ and the maximum is $\$ 19.99$. After your bids are recorded, only one of the lotteries will be randomly chosen for further use in the experiment. The other eight will be eliminated. [Are there any questions?]

\section{Choice of Lottery Phase}

Which lottery is chosen for further use in the experiment will be determined randomly by drawing a poker chip from a bucket containing nine chips numbered 1 through 9 . If chip 1 is drawn, the $10 \%$ chance-of-winning lottery is chosen. If chip 2 is drawn, the $20 \%$ chance-of-winning lottery is chosen. Similarly, chips 3 through 9 correspond to the $30 \%$ through $90 \%$ chance-of-winning lotteries. [Are there any questions?] 


\section{Purchase Price Determination Phase}

The purchase price for the right to play the lottery will be determined randomly in the range from $\$ 0$ to $\$ 19.99$ using 10 poker chips numbered 0 through 9 drawn from a bucket. There will be four draws - the first draw (using only the two chips numbered 0 and 1) will determine the first digit and the second though fourth draws (using all 10 chips) will determine the other three digits. [Are there any questions?]

If your bid (maximum willingness to pay) is greater than or equal to the purchase price, you pay the purchase price and play the lottery. If your bid is less than the purchase price, you do not play the lottery.

It is important to understand that, if you play the lottery, you pay the randomly determined purchase price rather than your bid price (unless your bid is exactly equal to the purchase price). This is why your best strategy is to submit a bid equal to your maximum willingness to pay for the right to play a lottery.

After the purchase price is determined, a random number will be drawn to determine which lotteries pay $\$ 20$ and which lotteries pay $\$ 0$. [Are there any questions?]

\section{How is my final cash payment determined?}

If you play the lottery, your final cash payment $=$ your $\$ 20$ endowment + your lottery winnings $(\$ 20$ or $\$ 0)$ - the lottery purchase price. For example, suppose your bid for the chosen lottery is $\$ 10$. If the random purchase price is $\$ 8.75$ then your bid is greater than the purchase price, so you have bought the right to play the lottery and the price you pay is $\$ 8.75$ (not your $\$ 10$ bid price). If you win the lottery your final cash payment $=\$ 20$ endowment $+\$ 20$ lottery winnings - $\$ 8.75$ purchase price $=\$ 31.25$. If you do not win the lottery your final cash payment $=\$ 20$ endowment + $\$ 0$ lottery winnings $-\$ 8.75$ purchase price $=\$ 11.25$.

If you do not play the lottery, your final cash earnings $=\$ 20$ endowment.

[Are there any questions?]

\section{What is the largest final cash payment possible?}

The largest possible cash payment is $\$ 40$. This outcome will occur only if the random purchase price for the chosen lottery is $\$ 0$ and you win the lottery. Your final payment would thus be $\$ 20$ (endowment) + \$20 (lottery winnings) $\$ 0$ (purchase price) $=\$ 40$. Note that there is a 1 in 2,000 $(.05 \%)$ chance that any one purchase price in the range from $\$ 0$ to $\$ 19.99$ will be drawn.

\section{What is the smallest final cash payment possible?}

The smallest possible cash payment is $\$ .01$. This outcome will occur only if the random purchase price for the chosen lottery is $\$ 19.99$, your bid for this lottery is $\$ 19.99$, and you lose the lottery. Your final payment would thus be $\$ 20$ (endowment) $+\$ 0$ (lottery winnings) - $\$ 19.99$ (purchase price) $=\$ .01$. 


\section{What is the exact sequence of events in the experiment?}

1. Everyone enters their nine bids associated with the nine lotteries on their Experiment Record Sheet. Remember, your bid price is the maximum price that you are willing to pay to play a specific lottery. You do not actually pay what you bid unless the randomly determined purchase price is exactly equal to the bid price. In all other cases, if you play a lottery, the purchase price is less than the bid.

[Enter nine practice bids on your Practice Record Sheet now.]

2. When everyone is finished entering their bids, the experiment monitor will collect all of the record sheets. The monitor will then visit each participant and each will draw a poker chip to determine which one of the nine lotteries will be utilized for that individual in the remainder of the experiment.

[Demonstration of lottery choice via chip draw.]

[In this practice exercise, enter this number yourself on the Practice Record Sheet after "Lottery Chosen".]

3. The random purchase price $(\$ 00.00$ - \$19.99) will then be determined via four poker chip draws. This purchase price will be displayed to everyone and will apply to all lotteries.

[Demonstration of purchase price determination via four chip draws.]

[Enter this amount on the Practice Record Sheet after "Purchase Price Chosen".]

4. Everyone can now determine if they purchased the right to play the lottery. If your bid is greater than or equal to the purchase price, you pay the purchase price and play the lottery. If your bid is less than the purchase price, you pay nothing and do not play the lottery.

[Circle "YES (play lottery)" or "NO (Final Cash Payment = \$20)" on the Practice Record Sheet as appropriate.]

5. The random number $(0-9)$ used to determine the lottery outcome will then be chosen via a poker chip draw. This number will be displayed to everyone and will apply to all lotteries.

[Demonstration of lottery outcome determination via chip draw.]

[If you played the lottery, enter this number on the Practice Record Sheet after "\# drawn".]

6. Each individual that played a lottery can now determine if they won the $\$ 20$ lottery. If the number times 10 is less than the stated chance of winning, the lottery pays $\$ 20$. Otherwise, the lottery pays $\$ 0$.

[After "WIN \$20?" on your Practice Record Sheet circle "YES" or "NO" as appropriate, then calculate your final cash payment on your Practice Record Sheet.]

7. At the end of the experiment, the monitor will call each participant to the front of the room one at a time. Please remain seated until you are called. In your presence, the monitor will determine your final cash payment using the procedures described previously. You will be paid this amount privately in cash and must sign a payment sheet for our financial records.

This is the end of the instructions. Are there any final questions? If not, it is time to begin the actual experiment to determine your cash earnings. Good luck to everyone!

[Display large wad of cash.] 


\section{Experiment Record Sheet}

Session:

Participant \#

Lottery

$\underline{\text { Your Bid to Purchase Lottery }(\$ 0-\$ 19.99)}$

1) $10 \%$ chance of winning $\$ 20$

$\$$

2) $20 \%$ chance of winning $\$ 20$

$\$$

3) $30 \%$ chance of winning $\$ 20$

$\$$

4) $\quad 40 \%$ chance of winning $\$ 20$

$\$$

5) $50 \%$ chance of winning $\$ 20$

$\$$

6) $60 \%$ chance of winning $\$ 20$

$\$$

7) $70 \%$ chance of winning $\$ 20$

$\$$

8) $80 \%$ chance of winning $\$ 20$

$\$$

9) $\quad 90 \%$ chance of winning $\$ 20$

$$
\$
$$

Do not write below this line.

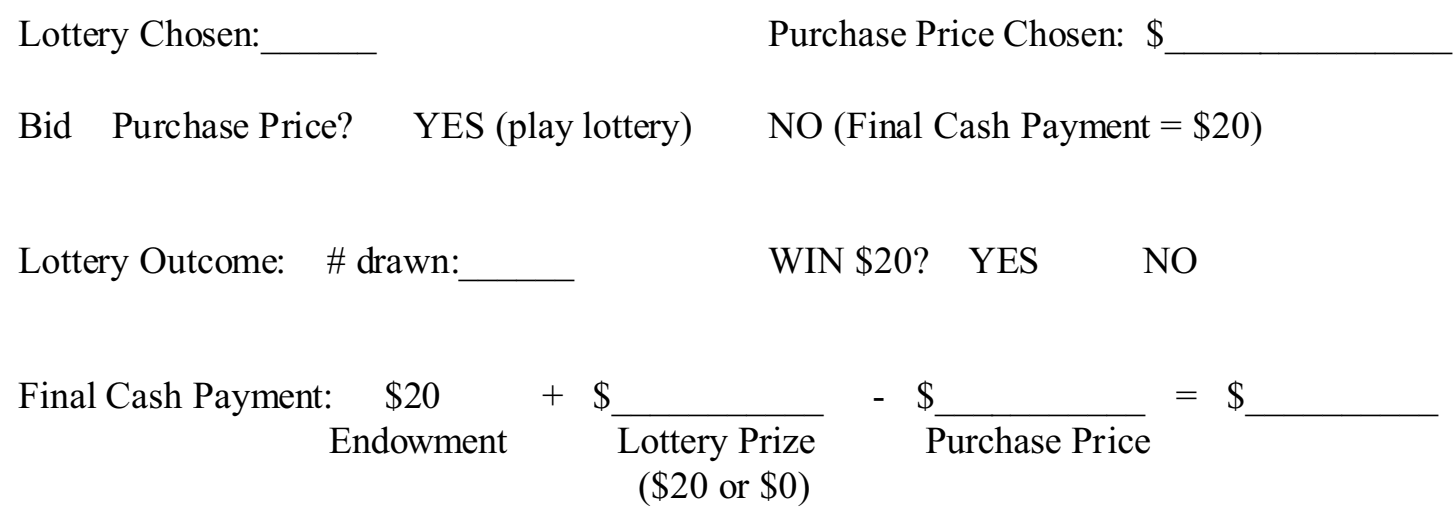




\section{Lottery Valuation Experiment Individual Bid Decision Sessions}

Step 1. Enter a bid (maximum willingness to pay) for each of the 9 lotteries. ( 9 bids in the $\$ 0-\$ 19.99$ range)

Step 2. Randomly choose 1 of the 9 lotteries (1 - 9) for each participant.

Step 3. Randomly choose the purchase price (\$0 - 19.99): $\$$

Step 4. Is your bid greater than or equal to the purchase price?

Result a. NO - you do not play the lottery. Your final cash payment is $\mathbf{\$ 2 0}$.

Result b. YES - you play the lottery and pay the purchase price from step 3.

Step 5. Randomly choose the lottery outcome (0 - 9):

Step 6. Is the step 5 number less than the lottery number chosen in step 2?

Result a. NO - you do not win the \$20 lottery. Your final cash payment is $\mathbf{\$ 2 0}$ - purchase price.

Result b. YES - you win the \$20 lottery. Your final cash payment is $\$ 20+\$ 20$ - purchase price.

Step 7. When your name is called, come to the desk at the front of the room to receive your final cash payment. 


\section{Appendix B - Instructions, Record Sheet, and Overhead for Sessions with Three-Person Groups}

This is an experiment in behavioral economics focusing on group valuation of events (called lotteries) that have uncertain outcomes. Your three-person group is starting with a money endowment of $\$ 60$. This $\$ 60$ can be used to purchase the right to play a lottery (i.e. buy a lottery ticket). Since the outcome of a lottery is uncertain, your group might win more money or lose some of the $\$ 60$ endowment through participation in the experiment. At the conclusion of the experiment your group will be paid its final earnings privately in cash. Each member of the group will receive a one-third share of the group earnings.

Before getting into the details of the experimental procedures and the decisions you will make, it is important that you understand exactly what is meant by the term "lottery".

\section{What is a lottery?}

In this experiment, a lottery is a chance to win a monetary prize of $\$ 60$. There are nine possible lotteries in today's experiment. The nine lotteries are associated with the following chances of winning: $90 \%, 80 \%, 70 \%, 60 \%, 50 \%$, $40 \%, 30 \%, 20 \%, 10 \%$. For example, consider the lottery with a $70 \%$ chance of winning. If this lottery was run many times, the player would win (receive $\$ 60$ ) $70 \%$ of the time and lose (receive $\$ 0$ ) $30 \%$ of the time. Using formal statistical terminology, the "expected value" or average payout from this lottery is .7 x $\$ 60=\$ 42$. This is the average payout after many repetitions, in any one lottery the payout is either $\$ 60$ or $\$ 0$. [Are there any questions?]

\section{How is the outcome of a lottery determined?}

To determine whether a lottery pays out $\$ 60$ or $\$ 0$, a number between 0 and 9 will be randomly drawn. The random number will be determined using 10 poker chips numbered 0 through 9 drawn from a bucket. If the number times 10 is less than the stated chance of winning $\$ 60$, the lottery pays $\$ 60$. If the number times 10 is greater than or equal to the stated chance of winning, the lottery pays $\$ 0$. For example, the $70 \%$ lottery pays $\$ 60$ if the random number drawn is $0,1,2,3,4,5$ or 6 . This lottery pays $\$ 0$ if the random number drawn is 7,8 , or 9 . [Are there any questions?]

\section{How do I purchase the right to play a lottery?}

Now that you understand how the lotteries work, it's time to explain how your group can purchase the right to play one of the nine lotteries. There are three phases to this process: a bid decision phase, a choice of lottery phase, and a purchase price determination phase.

\section{Bid Decision Phase}

In the bid decision phase your group will enter (on the attached Experiment Record Sheet) the maximum amount that it is willing to pay for the right to play each of the nine lotteries. These nine maximum willingness-to-pay decisions are your group's "bids" for the nine lotteries. The minimum bid is $\$ 0$ and the maximum is $\$ 59.99$. You have a maximum of 20 minutes to agree on your group's bid decisions. If you can not unanimously agree on your group's bid for a specific lottery, each group member will privately submit an individual bid and your group's bid will be the average of the three individual bids.

After your group's bids are recorded, only one of the lotteries will be randomly chosen for further use in the experiment. The other eight will be eliminated. [Are there any questions?] 
Which lottery is chosen for further use in the experiment will be determined randomly by drawing a poker chip from a bucket containing nine chips numbered 1 through 9 . If chip 1 is drawn, the $10 \%$ chance-of-winning lottery is chosen. If chip 2 is drawn, the $20 \%$ chance-of-winning lottery is chosen. Similarly, chips 3 through 9 correspond to the $30 \%$ through $90 \%$ chance-of-winning lotteries. [Are there any questions?]

\section{Purchase Price Determination Phase}

The purchase price for the right to play the lottery will be determined randomly in the range from $\$ 0$ to $\$ 59.99$ using 10 poker chips numbered 0 through 9 drawn from a bucket. There will be four draws - the first draw (using only the six chips numbered $0,1,2,3,4$, and 5) will determine the first digit and the second though fourth draws (using all 10 chips) will determine the other three digits. [Are there any questions?]

If your group's bid (maximum willingness to pay) is greater than or equal to the purchase price, your group pays the purchase price and plays the lottery. If your group's bid is less than the purchase price, your group does not play the lottery.

It is important to understand that, if your group plays the lottery, the group pays the randomly determined purchase price rather than the bid price (unless the bid is exactly equal to the purchase price). This is why your best strategy is to submit a bid equal to your group's maximum willingness to pay for the right to play a lottery.

After the purchase price is determined, a random number will be drawn to determine which lotteries pay $\$ 60$ and which lotteries pay $\$ 0$. [Are there any questions?]

\section{How is my final cash payment determined?}

If your group plays the lottery, your group's final cash payment $=$ your $\$ 60$ endowment + your lottery winnings ( $\$ 60$ or $\$ 0$ ) - the lottery purchase price. For example, suppose your group's bid for the chosen lottery is $\$ 30$. If the random purchase price is $\$ 26.25$ then your group's bid is greater than the purchase price, so your group has bought the right to play the lottery and the price paid is $\$ 26.25$ (not the $\$ 30$ bid price). If your group wins the lottery, your group's final cash payment $=\$ 60$ endowment $+\$ 60$ lottery winnings $-\$ 26.25$ purchase price $=\$ 93.75$. If your group does not win the lottery, your group's final cash payment $=\$ 60$ endowment $+\$ 0$ lottery winnings $-\$ 26.25$ purchase price $=\$ 33.75$.

If your group does not play the lottery, your group's final cash earnings $=\$ 60$ endowment.

[Are there any questions?]

\section{What is the largest final cash payment possible?}

The largest possible cash payment to a group is $\$ 120$. This outcome will occur only if the random purchase price for the chosen lottery is $\$ 0$ and your group wins the lottery. Your group's final payment would thus be $\$ 60$ (endowment) $+\$ 60$ (lottery winnings) - $\$ 0$ (purchase price) $=\$ 120$. Note that there is a 1 in $6,000(.017 \%)$ chance that any one purchase price in the range from $\$ 0$ to $\$ 59.99$ will be drawn.

\section{What is the smallest final cash payment possible?}

The smallest possible cash payment is $\$ .01$. This outcome will occur only if the random purchase price for the chosen lottery is $\$ 59.99$, your group's bid for this lottery is $\$ 59.99$, and your group loses the lottery. Your group's final payment would thus be $\$ 60$ (endowment) $+\$ 0$ (lottery winnings) - $\$ 59.99$ (purchase price) $=\$ .01$. 


\section{What is the exact sequence of events in the experiment?}

1. Every group enters their nine bids associated with the nine lotteries on their Experiment Record Sheet. Remember, your group's bid price is the maximum price that it is willing to pay to play a specific lottery. Your group does not actually pay what it bids unless the randomly determined purchase price is exactly equal to the bid price. In all other cases, if your group plays a lottery, the purchase price is less than the bid.

[Enter nine practice bids on your group's Practice Record Sheet now.]

2. When every group is finished entering their bids, the experiment monitor will collect all of the record sheets. The monitor will then visit each group and each will draw a poker chip to determine which one of the nine lotteries will be utilized for that group in the remainder of the experiment.

[Demonstration of lottery choice via chip draw.]

[In this practice exercise, enter this number yourself on the Practice Record Sheet after "Lottery Chosen".]

3. The random purchase price (\$00.00 - \$59.99) will then be determined via four poker chip draws. This purchase price will be displayed to everyone and will apply to all lotteries.

[Demonstration of purchase price determination via four chip draws.]

[Enter this amount on the Practice Record Sheet after "Purchase Price Chosen".]

4. Each group can now determine if it purchased the right to play the lottery. If the group's bid is greater than or equal to the purchase price, it pays the purchase price and plays the lottery. If the group's bid is less than the purchase price, it pays nothing and does not play the lottery.

[Circle "YES (play lottery)" or "NO (Final Cash Payment = \$60)" on the Practice Record Sheet as appropriate.]

5. The random number $(0-9)$ used to determine the lottery outcome will then be chosen via a poker chip draw. This number will be displayed to everyone and will apply to all lotteries.

[Demonstration of lottery outcome determination via chip draw.]

[If your group played the lottery, enter this number on the Practice Record Sheet after “\# drawn”.]

6. Each group that played a lottery can now determine if it won the $\$ 60$ lottery. If the number times 10 is less than the stated chance of winning, the lottery pays $\$ 60$. Otherwise, the lottery pays $\$ 0$.

[After "WIN \$60?" on your Practice Record Sheet circle "YES” or "NO" as appropriate, then calculate the group's final cash payment on your Practice Record Sheet.]

7. At the end of the experiment, the monitor will call each group to the front of the room one at a time. Please remain seated until your group is called. In your presence, the monitor will determine your group's final cash payment using the procedures described previously. Each member of the group will be paid a one-third share of this amount privately in cash and must sign a payment sheet for our financial records.

This is the end of the instructions. Are there any final questions? If not, it is time to begin the actual experiment to determine your cash earnings. Good luck to everyone!

[Display large wad of cash.] 


\section{Experiment Record Sheet}

Session:

Lottery

1) $10 \%$ chance of winning $\$ 60$

2) $20 \%$ chance of winning $\$ 60$

3) $30 \%$ chance of winning $\$ 60$

4) $\quad 40 \%$ chance of winning $\$ 60$

5) $50 \%$ chance of winning $\$ 60$

6) $60 \%$ chance of winning $\$ 60$

7) $70 \%$ chance of winning $\$ 60$

8) $80 \%$ chance of winning $\$ 60$

9) $\quad 90 \%$ chance of winning $\$ 60$
Group \#

$\underline{\text { Your Group's Bid to Purchase Lottery }(\$ 0-\$ 59.99)}$

$\$$

$\$$

$\$$

$\$$

$\$$

$\$$

$\$$

$\$$

$\$$

Do not write below this line.

Lottery Chosen:

Bid $\geq$ Purchase Price? $\quad$ YES (play lottery)

Lottery Outcome: \# drawn:

Final Cash Payment: $\quad \$ 60+\$$ Endowment
Purchase Price Chosen: \$

NO (Final Cash Payment $=\$ 60)$

WIN \$60? YES NO
$\$ \frac{}{\text { Purchase Price }}=\$$

Lottery Prize

(\$60 or $\$ 0$ ) 


\section{Lottery Valuation Experiment Group Bid Decision Sessions}

Step 1. Enter a bid (maximum willingness to pay) for each of the 9 lotteries. (9 bids in the $\$ 0$ - $\$ 59.99$ range)

Step 2. Randomly choose 1 of the 9 lotteries (1 - 9) for each group.

Step 3. Randomly choose the purchase price (\$0 - 59.99): $\$$

Step 4. Is your group's bid greater than or equal to the purchase price?

Result a. NO - your group does not play the lottery.

Your group's final cash payment is $\mathbf{\$ 6 0}$.

Result b. YES - your group plays the lottery and pays the purchase price.

Step 5. Randomly choose the lottery outcome (0 - 9):

Step 6. Is the step 5 number less than the lottery number chosen in step 2?

Result a. NO - your group does not win the $\$ 60$ lottery. Your group's final cash payment is $\$ 60$ - purchase price.

Result b. YES - your group wins the \$60 lottery. Your group's final cash payment is $\$ 60+\$ 60$ - purchase price.

Step 7. When your group's number is called, come to the desk at the front of the room to receive your final cash payment. 


\section{Group Lottery Decision}

You will now make bid decisions as a member of a randomly chosen three-person group.

The bid and lottery determination processes will be identical to those that have already been described WITH THE FOLLOWING EXCEPTIONS:

1. Your three-person group will start with a money endowment of $\$ 60$.

2. A lottery will be the chance to win $\$ 60$.

3. Each member of the group will receive a one-third share of group earnings.

4. For each of the lotteries the maximum bid will now be $\$ 59.99$ instead of $\$ 19.99$.

5. You will have a maximum of 20 minutes to agree on your group's bid decisions. If you can not unanimously agree on your group's bid for a specific lottery, each group member will privately submit an individual bid and your group's bid will be the average of the three individual bids.

6. The purchase price will be randomly determined in the range from $\$ 0$ to \$59.99. As such, the first draw will now use six chips numbered $0,1,2,3,4,5$.

7. The largest cash payment to a group will be $\$ 120$. The smallest cash payment will still be $\$ .01$.

Any there any questions? 